\title{
Factors influencing the production of volatile phenols by wine lactic acid bacteria
}

\author{
Isa Silva, Francisco M. Campos, Tim Hogg, José António Couto* \\ CBQF/Escola Superior de Biotecnologia, Universidade Católica Portuguesa, Rua Dr. António Bernardino de Almeida, 4200-072 Porto, Portugal
}

Keywords:

Wine

Lactic acid bacteria

Volatile phenols

p-Coumaric acid

$\mathrm{NAD}^{+} / \mathrm{NADH}$ balance

\begin{abstract}
A B S T R A C T
This work aimed to evaluate the effect of certain factors on the production of volatile phenols from the metabolism of $p$-coumaric acid by lactic acid bacteria (LAB) (Lactobacillus plantarum, L. collinoides and Pediococcus pentosaceus). The studied factors were: $\mathrm{pH}$, L-malic acid concentration, glucose and fructose concentrations and aerobic/anaerobic conditions. It was found that, in the pH range of 3.5 to 4.5 , the higher the $\mathrm{pH}$ the greater the production of volatile phenols. This behaviour is correlated with the effect of $\mathrm{pH}$ on bacterial growth. Increasing levels of L-malic acid in the medium diminished the production of 4-vinylphenol (4VP) and stimulated the production of 4-ethylphenol (4EP) by L. plantarum NCFB 1752 and L. collinoides ESB 99. The conversion of 4VP into 4EP by the activity of the vinylphenol reductase may be advantageous to the cells in the presence of L-malic acid, presumably due to the generation of $\mathrm{NAD}^{+}$, a cofactor required by the malolactic enzyme. Relatively high levels of glucose $(20 \mathrm{~g} / \mathrm{L})$ led to an almost exclusive production of $4 \mathrm{VP}$ by $L$. plantarum NCFB 1752, while at low concentrations $(\leq 5 \mathrm{~g} / \mathrm{L}), 4 \mathrm{EP}$ is mainly or solely produced. Part of the glucose may be diverted to the production of mannitol as an alternative pathway to regenerate NAD ${ }^{+}$. This is corroborated by the experiments done with fructose, a compound that can be used as an electron acceptor by some bacteria becoming reduced to mannitol. In anaerobiosis, the reduction of 4VP into 4EP is clearly favoured, which is consistent with the need to increase the availability of $\mathrm{NAD}^{+}$in these conditions. This study shows that the amount and the ratio $4 \mathrm{VP} / 4 \mathrm{EP}$ produced by LAB are greatly affected by certain environmental and medium composition factors. The behaviour of the bacteria seems to be driven by the intracellular NAD ${ }^{+} /$ NADH balance.
\end{abstract}

\section{Introduction}

Some wine microorganisms can produce volatile phenols (vinylphenols and ethylphenols) from grape-derived hydroxycinnamic acids ( $p$-coumaric and ferulic acids). Volatile phenols have characteristic aromas which, above a certain concentration threshold, have a negative effect on the overall aroma of a wine, imparting off-flavours described as "animal", "horse sweat", "leather" or "medicinal"; but at low concentrations $(<420 \mu \mathrm{g} / \mathrm{L}$ of a mixture of 4 -ethylphenol and 4-ethylguaiacol) have been cited as contributing positively to aroma complexity (Chatonnet et al., 1995; Fugelsang and Edwards, 2007; Ribéreu-Gayon et al., 2000).

The precursors of the volatile phenols are natural constituents of grape juice and wine - the hydroxycinnamic acids p-coumaric and ferulic acids (Chatonnet et al., 1995; Heresztyn, 1986). The conversion of these phenolic acids involves the sequential activity of two enzymes: the first is the cinnamate decarboxylase which decarboxylates the hydroxycinnamic acid into the corresponding vinylphenol (4-vinylphenol

\footnotetext{
* Corresponding author at: Escola Superior de Biotecnologia, Universidade Católica Portuguesa, Rua Dr. António Bernardino de Almeida, 4200-072 Porto, Portugal. Tel.: + 35122 5580027; fax: + 351225090351.

E-mail address: jacouto@esb.ucp.pt (J.A. Couto).
}

[4VP] from $p$-coumaric acid or 4-vinylguaiacol from ferulic acid), and the second is the vinylphenol reductase which reduces the vinylphenol into the corresponding ethylphenol (4-ethylphenol [4EP] from 4VP and 4-ethylguaicol from 4-vinylguaiacol) (Chatonnet et al., 1992; Heresztyn, 1986).

White wines contaminated with volatile phenols normally contain variable amounts of vinylphenols, at a $4 \mathrm{VP} / 4$-vinylguaiacol ratio of $1: 1$, but generally contain no ethylphenols. Contaminated red wines, on the other hand, contain small amounts of vinylphenols but they possess large quantities of ethylphenols, in a typical 4EP/4-ethylguaicol ratio of 8:1 (Chatonnet et al., 1992; Ribéreu-Gayon et al., 2000).

The contaminant yeasts Dekkera/Brettanomyces are recognised as the main organisms responsible for the production of volatile phenols (Heresztyn, 1986), although previous works have shown that some strains of lactic acid bacteria (LAB) are also capable of producing volatile phenols. Cavin et al. (1993) found that Lactobacillus and Pediococcus were able to metabolise phenolic acids. Chatonnet et al. (1992, 1995) compared the ability of LAB to synthesise volatile phenols with Dekkera/Brettanomyces. Some of the LAB strains studied were capable of producing large quantities of 4VP, but only traces of ethylphenols. Only L. plantarum was capable of producing significant quantities of 4EP, however in much lower concentrations than those produced by Dekkera/Brettanomyces. Working with lactobacilli isolated from whisky distilleries, van Beek and Priest (2000) have shown 
that several strains were also able to produce volatile phenols from hydroxycinnamic ( $p$-coumaric and ferulic) acids. The authors also found that while most strains produced vinylphenols only, $L$. plantarum and $L$. crispatus were capable of producing ethylphenols from these phenolic acids. More recently, Couto et al. (2006) have shown that $37 \%$ of the strains studied (thirty five strains, twenty species) were capable of producing volatile phenols from $p$-coumaric acid in culture medium, although only $9 \%$ could produce $4 \mathrm{EP}$.

The factors that may influence the capacity of LAB to produce volatile phenols and the ratio vinylphenols/ethylphenols obtained from this activity are not well known. Therefore, the objective of this work was to study the influence of certain parameters ( $\mathrm{pH}, \mathrm{L}-\mathrm{malic}$ acid concentration, glucose and fructose concentrations and aerobic/ anaerobic conditions) on the production of volatile phenols by $L$. plantarum, $L$. collinoides and P. pentosaceus.

\section{Materials and methods}

\subsection{Bacteria and growth conditions}

The LAB strains L. plantarum NCFB 1752, P. pentosaceus NCFB 990 (National Culture of Food Bacteria, Reading, England) and L. collinoides ESB 99 (Escola Superior de Biotecnologia - UCP, Porto, Portugal (Couto and Hogg, 1994)) were used in this work. These strains were chosen due to their ability to convert $p$-coumaric acid into 4VP and/or 4EP as demonstrated by Couto et al. (2006).

Cultures were grown to late exponential phase in an MRS medium (Lab M, Lancashire, United Kingdom) at $25^{\circ} \mathrm{C}$. The initial pH was adjusted to 4.5 with a concentrated $(6 \mathrm{~mol} / \mathrm{L}) \mathrm{HCl}$ solution before sterilisation $\left(121^{\circ} \mathrm{C}, 15 \mathrm{~min}\right)$. After sterilisation, ethanol $(99.5 \% \mathrm{v} / \mathrm{v})$ was added to the medium to obtain a final concentration of $5 \% \mathrm{v} / \mathrm{v}$. Cultures were maintained on slants prepared with MRS with $2 \%$ agar (Pronadisa, Madrid, Spain), pH 4.5, 5\% v/v ethanol, at $4{ }^{\circ} \mathrm{C}$, with monthly transfers to maintain strain viability.

\subsection{Production of volatile phenols under different growth conditions}

To study the influence of $\mathrm{pH}$ on the production of volatile phenols by LAB, cultures in late exponential phase were transferred to an MRS medium with $5 \% \mathrm{v} / \mathrm{v}$ ethanol supplemented with $50 \mathrm{mg} / \mathrm{L}$ of $p$ coumaric acid (trans-4-hydroxycinnamic acid; 98\% purity, SigmaAldrich, Steinheim, Germany), with pH values ranging from 3.5 to 4.5. The different initial $\mathrm{pH}$ values were adjusted with a concentrated ( $6 \mathrm{~mol} / \mathrm{L}) \mathrm{HCl}$ solution before sterilisation $\left(121^{\circ} \mathrm{C}, 15 \mathrm{~min}\right)$. A concentrated solution of $p$-coumaric acid was prepared in ethanol $(99.5 \% \mathrm{v} / \mathrm{v})$ and added to the growth medium, after sterilisation. Cultures were incubated at $25^{\circ} \mathrm{C}$, without agitation, until stationary growth phase.

The effect of the presence of malic acid was studied in MRS medium with $5 \% \mathrm{v} / \mathrm{v}$ ethanol and $50 \mathrm{mg} / \mathrm{L}$ of $p$-coumaric acid ( $\mathrm{pH} 4.5$ ) to which L-malic acid from Merck (Darmstadt, Germany) was added to final concentrations of $0,0.1,2$ and $4 \mathrm{~g} / \mathrm{L}$. Cultures were incubated at $25^{\circ} \mathrm{C}$, without agitation, until stationary growth phase.

The influence of glucose and fructose on the production of volatile phenols by LAB was studied in modified MRS medium with $5 \% \mathrm{v} / \mathrm{v}$ ethanol and final concentrations of glucose adjusted to $0,1,3,5$ and $20 \mathrm{~g} / \mathrm{L}$, and fructose added to 5 and $20 \mathrm{~g} / \mathrm{L}$ ( $\mathrm{pH} 4.5$ ). In all the experiments the medium was supplemented with $50 \mathrm{mg} / \mathrm{L}$ of $p$ coumaric acid. Cultures were incubated at $25^{\circ} \mathrm{C}$, without agitation, until stationary growth phase.

The influence of oxygen on the production of volatile phenols by LAB was studied comparing aerobic versus anaerobic conditions. Cultures were grown in aerobic conditions in $100 \mathrm{ml}$ of modified MRS medium with $5 \% \mathrm{v} / \mathrm{v}$ ethanol, either with 3 or $20 \mathrm{~g} / \mathrm{L}$ of glucose $(\mathrm{pH}$ 4.5), in $250 \mathrm{~mL}$ loosely capped Schott flasks with agitation (150 rpm) at $25{ }^{\circ} \mathrm{C}$. Anaerobic conditions were achieved by boiling the medium for $5 \mathrm{~min}$ and sparging the broth and the headspace with nitrogen gas for 15 and $5 \mathrm{~min}$, respectively, to remove air and traces of oxygen. Resazurin ( $1 \mathrm{mg} / \mathrm{L})$ (Sigma) was added as an indicator of redox potential. The medium was then autoclaved $\left(121^{\circ} \mathrm{C}, 15 \mathrm{~min}\right)$. Cultures in $250 \mathrm{~mL}$ tightly capped Schott flasks were incubated statically at $25^{\circ} \mathrm{C}$.

Cellular growth was monitored daily by measuring the absorbance at $660 \mathrm{~nm}$, using a UV-VIS Nicolet evolution 300 spectrophotometer (Thermo Electron Corporation, Cambridge, UK) and optical cells of $1 \mathrm{~cm}$ path length. Dilutions with distilled water were made when the optical density value exceeded the linearity limit of Beer-Lambert's law. When cultures reached the stationary phase, samples were taken for the quantification of volatile phenols. Assays were made in duplicate or triplicate.

\subsection{Analysis of volatile phenols}

The samples were centrifuged at $3000 \mathrm{~g}$ for $10 \mathrm{~min}$ and the supernatants were treated and analysed according to the method described by Bertrand (1981). $50.0 \mu \mathrm{L}$ of 4-decanol (internal standard) was added to $50 \mathrm{~mL}$ of culture medium. This mixture was successively extracted with 4,2 and $2 \mathrm{~mL}$ of ether/hexane (1:1) by stirring for $5 \mathrm{~min}$. The organic phases were collected, mixed and concentrated under a stream of nitrogen to approximately half of the initial volume. One microliter of the extract was injected into a Perkin Elmer GC-FID (Shelton, CT, USA). The column employed was a FFAP type (BP $21.50 \mathrm{~m} \times 0.25 \mathrm{~mm} \times 0.2 \mu \mathrm{m}$ ), from SGE (Austin, Texas). The injector (split/splitless) was heated to $220{ }^{\circ} \mathrm{C}$ with a split flow of $30 \mathrm{~mL} / \mathrm{min}$ and a splitless time of $0.5 \mathrm{~min}$. The carrier gas flow was adjusted to $1 \mathrm{~mL} / \mathrm{min}$. The temperature of the oven was maintained at $4{ }^{\circ} \mathrm{C}$ for $1 \mathrm{~min}$ and was then increased at a rate of $2{ }^{\circ} \mathrm{C} / \mathrm{min}$ up to $220^{\circ} \mathrm{C}$. This temperature was then maintained for $30 \mathrm{~min}$. The detection limit of the method was $0.05 \mathrm{mg} / \mathrm{L}$ for $4 \mathrm{VP}$ and $0.01 \mathrm{mg} / \mathrm{L}$ for 4EP.

\section{Results and discussion}

\subsection{Effect of $\mathrm{pH}$ on the production of volatile phenols}

In the $\mathrm{pH}$ range investigated in this work (3.5 to 4.5 ), it was possible to observe that the higher the $\mathrm{pH}$ the greater the production of volatile phenols by the three bacterial strains studied (Table 1 ). This behaviour is correlated with the effect of $\mathrm{pH}$ on bacterial growth. Final $\mathrm{OD}_{660}$ values of the liquid cultures (recorded at the stationary growth phase) were considerably lower at $\mathrm{pH} 3.5$ than at 4 and 4.5 . The results show that the production of volatile phenols is more affected by $\mathrm{pH}$ variations in LAB than in Dekkera bruxelensis (recognised as the main organism responsible for the production of volatile phenols in

Table 1

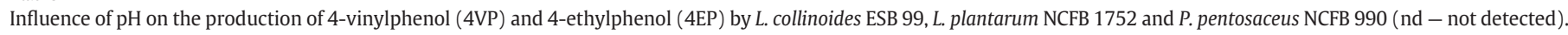

\begin{tabular}{|c|c|c|c|c|c|c|c|c|c|c|}
\hline & & \multicolumn{3}{|c|}{ L. collinoides ESB 99} & \multicolumn{3}{|c|}{ L. plantarum NCFB 1752} & \multicolumn{3}{|c|}{ P. pentosaceus NCFB 990} \\
\hline & & {$[4 \mathrm{VP}](\mathrm{mg} / \mathrm{L})$} & [4EP] (mg/L) & Final $\mathrm{OD}_{660}$ & {$[4 \mathrm{VP}](\mathrm{mg} / \mathrm{L})$} & {$[4 \mathrm{EP}](\mathrm{mg} / \mathrm{L})$} & Final $\mathrm{OD}_{660}$ & {$[4 \mathrm{VP}](\mathrm{mg} / \mathrm{L})$} & {$[4 \mathrm{EP}](\mathrm{mg} / \mathrm{L})$} & Final $\mathrm{OD}_{660}$ \\
\hline \multirow[t]{3}{*}{$\mathrm{pH}$} & 3.5 & $0.91 \pm 0.01$ & nd & $0.17 \pm 0.01$ & $1.21 \pm 1.04$ & $0.04 \pm 0.00$ & $0.48 \pm 0.54$ & $0.56 \pm 0.39$ & $0.04 \pm 0.00$ & $0.07 \pm 0.01$ \\
\hline & 4.0 & $1.08 \pm 0.08$ & $6.71 \pm 0.05$ & $3.35 \pm 0.04$ & $3.27 \pm 1.61$ & $0.90 \pm 0.50$ & $1.27 \pm 0.09$ & $26.69 \pm 0.37$ & $0.05 \pm 0.00$ & $0.87 \pm 0.27$ \\
\hline & 4.5 & $2.35 \pm 0.21$ & $11.80 \pm 2.12$ & $4.36 \pm 0.06$ & $20.68 \pm 2.94$ & $0.62 \pm 0.44$ & $2.89 \pm 0.25$ & $30.32 \pm 1.31$ & $0.04 \pm 0.00$ & $1.99 \pm 0.05$ \\
\hline
\end{tabular}



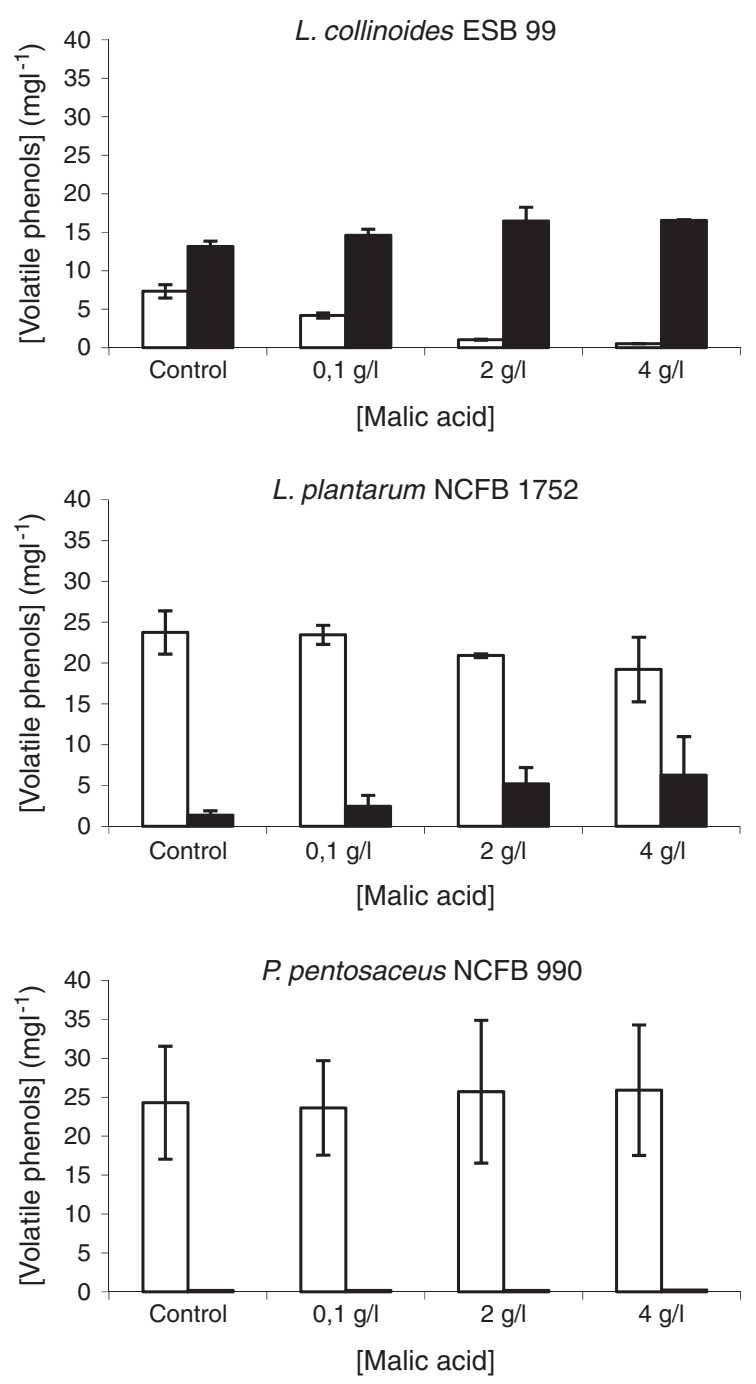

Fig. 1. Effect of L-malic acid on the production of 4-vinylphenol (white bars) and 4ethylphenol (black bars) by L. collinoides ESB 99, L. plantarum NCFB 1752 and $P$. pentosaceus NCFB 990. Results are the average values of two experiments (with standard deviation).

wines (Chatonnet et al., 1995; Heresztyn, 1986)). Benito et al. (2009) reported that the conversion of $p$-coumaric acid into 4EP by this organism is complete in the pH range of 2.6 to 4.2. Harris et al. (2010) did not observe any significant impact of $\mathrm{pH}$ on growth of most of the Dekkera species studied in the $\mathrm{pH}$ range of 3.0 to 5.0.

\subsection{Effect of L-malic acid on the production of volatile phenols}

The presence of L-malic acid in the culture medium, especially in the concentrations of 2 and $4 \mathrm{~g} / \mathrm{L}$, slightly stimulated the growth of the three strains as expressed by the final biomasses obtained (data not shown). The stimulatory effect of malic acid on the growth of wine LAB, such as $O$. oeni, is well documented (Firme et al., 1994; Kunkee, 1991; Loubiere et al., 1992; Saguir and Manca de Nadra, 1996). Cox and Henick-Kling (1989, 1995) were able to demonstrate, based on the chemiosmotic theory, the biochemical benefit of malolactic fermentation, as an ATP yielding process. The results of the present work show that L-malic acid markedly influences the production of volatile phenols, stimulating the production of 4EP while diminishing the amount of 4VP released to the culture medium by L. collinoides ESB 99 and L. plantarum NCFB 1752 (Fig. 1). A possible explanation for these results is that the conversion of 4VP into $4 \mathrm{EP}$, by the activity of the vinylphenol reductase, may be advantageous to the cells in the presence of L-malic acid, presumably due to the production of $\mathrm{NAD}^{+}$by the reduction step of the hydroxycinnamic acids metabolic pathway. Indeed, the enzyme involved in the malolactic fermentation by $\mathrm{LAB}$, the malolactic enzyme, requires the presence of $\mathrm{NAD}^{+}$cofactor and bivalent ions, particularly $\mathrm{Mn}^{2+}$, for the decarboxylation of L-malic acid into L-lactic acid and $\mathrm{CO}_{2}$ (Jackson, 2008). The production of volatile phenols by $P$. pentosaceus NCFB 990 was not affected by the different levels of malic acid studied. In fact, this species was unable to synthesise 4EP (only trace amounts) in any of the scenarios investigated.

\subsection{Effect of glucose and fructose concentrations on the production of volatile phenols}

The concentration of glucose in the culture medium strongly influenced the behaviour of L. plantarum NCFB 1752 (Fig. 2). This organism produced mainly $4 \mathrm{VP}$ in the presence of $20 \mathrm{~g} / \mathrm{L}$ of glucose, while at $5 \mathrm{~g} / \mathrm{L}$ and lower concentrations, 4EP is mainly or solely produced. When homofermentative or facultatively heterofermentative LAB (such as L. plantarum) grow on hexose substrates such as glucose, a typical homolactic fermentation is carried out. Pyruvate is reduced to lactic acid by the lactate dehydrogenase, thereby reoxidizing
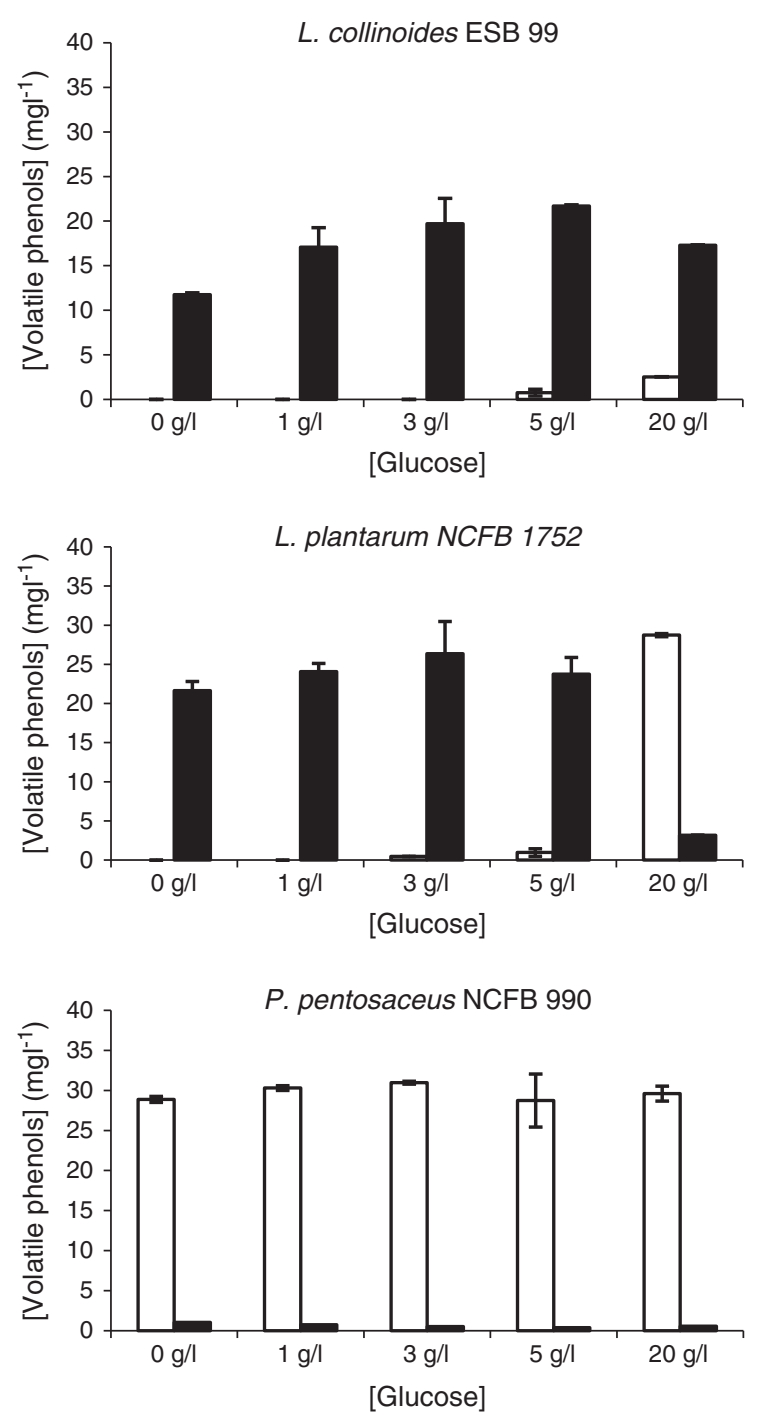

Fig. 2. Effect of glucose concentration on the production of 4-vinylphenol (white bars) and 4-ethylphenol (black bars) by L. collinoides ESB 99, L. plantarum NCFB 1752 and $P$. pentosaceus NCFB 990. Results are the average values of two experiments (with standard deviation). 

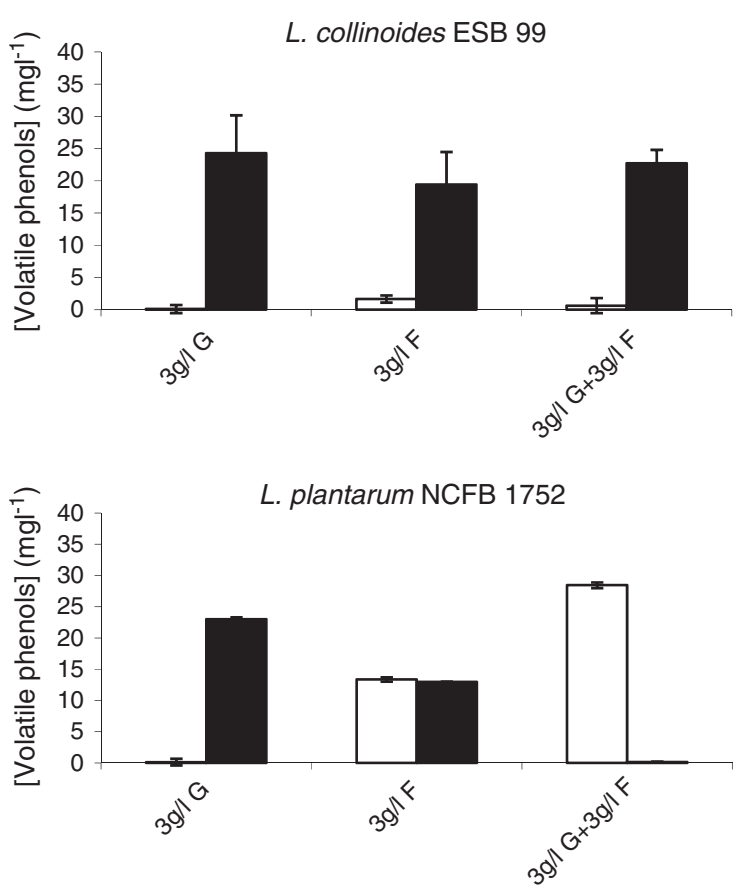

Fig. 3. Effect of fructose concentration on the production of 4-vinylphenol (white bars) and 4-ethylphenol (black bars) by L. collinoides ESB 99 and L. plantarum NCFB 1752. G - glucose; F - fructose. Results are the average values of two experiments (with standard deviation).

the NADH formed during the early glycolytic steps (Wisselink et al., 2002). The results of this work suggest that at relatively high levels of glucose $(20 \mathrm{~g} / \mathrm{L})$, part of the carbohydrate might be diverted to the production of mannitol. The biosynthesis of this polyol can be performed by homofermentative/facultatively heterofermentative LAB from the glycolysis intermediate fructose 6-phosphate (Wisselink et al., 2002), functioning as an alternative pathway, instead of lactate formation, to regenerate $\mathrm{NAD}^{+}$. In these conditions, cells might not need to synthesise $\mathrm{NAD}^{+}$(presumably the co-enzyme formed from the reduction of $4 \mathrm{VP}$ ) by the reduction step of $p$-coumaric acid metabolism, which explains the accumulation of 4VP. A more comprehensive metabolic characterization of $L$. plantarum, concerning the effect of glucose concentration on the conversion of phenolic acids, will be taken into account in future work. The behaviour of $L$. collinoides ESB 99 was only slightly affected by the variation of the glucose concentration. Heterolactic bacteria (such as L. collinoides) are unable to synthesise mannitol from glucose, therefore this via cannot be used as an alternative pathway to regenerate $\mathrm{NAD}^{+}$(Wisselink et al., 2002). This explains the advantage of this strain in regenerating $\mathrm{NAD}^{+}$through the reduction of $4 \mathrm{VP}$ into $4 \mathrm{EP}$. The production of volatile phenols by $P$. pentosaceus NCFB 990 was not affected by the glucose concentration. Low levels of glucose $(0-5 \mathrm{~g} / \mathrm{L})$ affected the growth of all strains (results not shown), however they were still able to produce significant amounts of volatile phenols.

The utilisation of fructose as the sole carbon and energy source or in combination with glucose strongly influenced the production of volatile phenols by $L$. plantarum NCFB 1752, especially at low levels of sugar concentration ( $3 \mathrm{~g} / \mathrm{L}$ ) (Fig. 3). When fructose is used instead of glucose or in combination with glucose, the production of 4EP is diminished while the production of $4 \mathrm{VP}$ is favoured. This effect might be related with the reduction of fructose into mannitol, accompanied by the regeneration of $\mathrm{NAD}^{+}$. The fermentative metabolism of hexoses can result in the generation of excess reduced $\mathrm{NAD}^{+}$ $(\mathrm{NADH})$. To maintain an acceptable redox balance, the bacteria must be able to regenerate $\mathrm{NAD}^{+}$(Jackson, 2008). It is known that some species reduce fructose to mannitol, presumably for this purpose (Nielsen and Richelieu, 1999; Salou et al., 1994). In these conditions cells wouldn't need to synthesise $\mathrm{NAD}^{+}$by the reduction step of $p$-coumaric acid metabolism, thus leading to the accumulation of 4VP. A similar effect of the addition of fructose was found in the heterofermentative strain $L$. collinoides ESB 99 but to a lesser extent than in L. plantarum NCFB 1752.

\subsection{Effect of the oxygen level the production of volatile phenols}

The level of oxygen present in the culture medium strongly influenced the production o volatile phenols by the bacterial strains studied. In aerobic conditions, the lactobacilli only produced 4VP (Fig. 4). In anaerobiosis, the total concentration of the volatile phenols $(4 \mathrm{VP}+4 \mathrm{EP})$ produced was lower, however the reduction of $4 \mathrm{VP}$ into $4 \mathrm{EP}$ was clearly favoured. Since under reductive conditions cells may experience a shortage of $\mathrm{NAD}^{+}$, the reduction of 4VP into 4EP would allow the cells to increase the availability of $\mathrm{NAD}^{+}$. Under low oxygen concentrations the availability of $\mathrm{NAD}^{+}$can be limited so that carbohydrate metabolism is inhibited (Jackson, 2008). It is known that a number of flavoprotein oxidase enzymes are responsible for the direct interaction of LAB with oxygen (Condon, 1987). This makes possible the oxidation of $\mathrm{NADH}_{2}$ with oxygen serving as the final electron acceptor.

As mentioned in the introduction, the conversion of phenolic acids into volatile phenols is a two step process comprising the decarboxylation of the precursor and the reduction of the vinylphenol intermediate. The results of this work suggest that the conversion of $4 \mathrm{VP}$ into 4EP, catalyzed by the vinylphenol reductase, may lead to the re-oxidation of $\mathrm{NADH}$. An analogous statement was made by Fugelsang and Edwards (2007) for Brettanomyces/Dekkera: since a reduced cofactor is generally required for the enzymatic reduction activity, it is likely that the production of volatile phenols, specifically the reduction of $4 \mathrm{VP}$ into $4 \mathrm{EP}$, is a source of $\mathrm{NAD}^{+}$during growth of this organism in red wines.

This study highlights the capacity of wine lactic acid bacteria to produce volatile phenols and that the amount and the ratio 4VP/4EP produced are considerably affected by environmental and medium composition factors. The behaviour of the bacteria seems to be driven by the intracellular $\mathrm{NAD}^{+} / \mathrm{NADH}$ balance. Further research is required
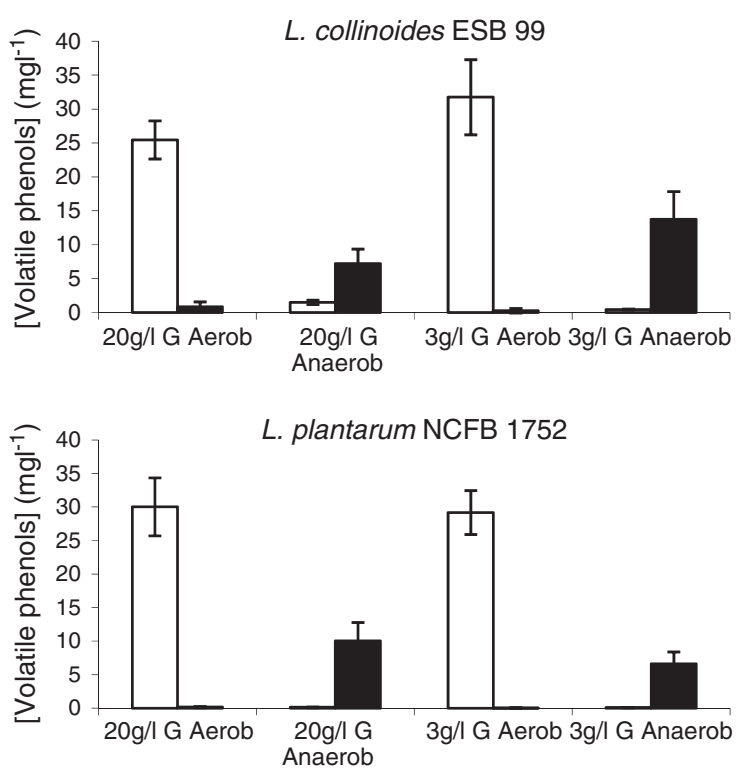

Fig. 4. Effect of oxygen on the production of 4-vinylphenol (white bars) and 4-ethylphenol (black bars) by L. collinoides ESB 99 and L. plantarum NCFB 1752. G - glucose. Results are the average values of three experiments (with standard deviation). 
to elucidate the real impact of the metabolic activity of lactic acid bacteria on the levels of volatile phenols found in wines.

\section{Acknowledgement}

The authors would like to thank FCT (Fundação para a Ciência e Tecnologia) for funding this research via project POCTI/AGR/61331/ 2004

\section{References}

Benito, S., Palomero, F., Morata, A., Calderon, F., Suarez-Lepe, J.A., 2009. Factors affecting the hydroxycinnamate decarboxylase/vinylphenol reductase activity of Dekkera/ Brettanomyces: application for Dekkera/Brettanomyces control in red wine making. Journal of Food Science 74, M15-M22.

Bertrand, A., 1981. Formations de substances volatiles au cours de la fermentation alcoolique. Incidence sur la qualité des vins. Colloque Societé Française de Microbiologie, Reims, pp. 251-267.

Cavin, J., Andioc, V., Etievant, P., Diviès, C., 1993. Ability of wine lactic acid bacteria to metabolize phenol carboxylic acids. American Journal of Enology and Viticulture $44,76-80$.

Chatonnet, P., Dubourdieu, D., Boidron, J., Pons, M., 1992. The origin of ethylphenols in wines. Journal of Food Science and Agriculture 60, 165-178.

Chatonnet, P., Dubordieu, D., Boidron, J., 1995. The influence of Brettanomyces/Dekkera sp. and lactic acid bacteria on the ethylphenol content of red wines. American Journal of Enology and Viticulture 46, 463-468

Condon, S., 1987. Responses of lactic acid bacteria to oxygen. FEMS Microbiology Letters 46, 269-280.

Couto, J.A., Hogg, T.A., 1994. Diversity of ethanol-tolerant lactobacilli isolated from Douro fortified wine: clustering and identification by numerical analysis of electrophoretic protein profiles. The Journal of Applied Bacteriology 76, 487-491.

Couto, J.A., Campos, F., Figueiredo, R., Hogg, T.A., 2006. Ability of lactic acid bacteria to produce volatile phenols. American Journal of Enology and Viticulture 57, 166-171.
Cox, D.J., Henick-Kling, T., 1989. Chemiosmotic energy from malolactic fermentation. Journal of Bacteriology 171, 5750-5752.

Cox, D.J., Henick-Kling, T., 1995. Protonmotive force and ATP generation during malolactic fermentation. American Journal of Enology and Viticulture 46, 319-323.

Firme, M.P., Leitão, M.C., San Romão, M.V., 1994. The metabolism of sugar and malic acid by Leuconostoc oenos, effect of malic acid, pH and aeration conditions. The Journal of Applied Bacteriology 76, 173-181.

Fugelsang, K., Edwards, C., 2007. Wine Microbiology, Practical Applications and Procedures, second ed. The Chapman \& Hall Enology Library, UK.

Harris, V., Jiranek, V., Ford, C.M., Grbin, P.R., 2010. Inhibitory effect of hydroxycinnamic acids on Dekkera spp. Applied Microbial and Cell Physiology 86, 721-729.

Heresztyn, T., 1986. Metabolism of volatile phenolic compounds from hydroxycinnamic acids by Brettanomyces yeast. Archives of Microbiology 146, 96-98.

Jackson, R., 2008. Wine Science, Principles and Applications, Third ed. Academic Press.

Kunkee, R.E., 1991. Some roles of malic acid in the malolactic fermentation in wine making. FEMS Microbiology Reviews 88, 55-72.

Loubiere, P., Salou, P., Leroy, M.J., Lindley, N.D., Pareilleux, A., 1992. Electrogenic malate uptake and improved growth energetics of the malolactic bacterium Leuconostoc oenos grown on glucose-malate mixtures. Journal of Bacteriology 174, 5302-5308.

Nielsen, J.C., Richelieu, M., 1999. Control of flavor development in wine during and after malolactic fermentation by Oenococcus oeni. Applied and Environmental Microbiology $65,740-745$

Ribéreu-Gayon, P., Dubourdieu, D., Donéche, B., Lonvaud, A., 2000. Handbook of Enology Volume II, The Chemistry of Wine and Stabilization and Treatments, Second ed. John Wiley \& Sons Ltd, UK.

Saguir, F.M., Manca de Nadra, M.C., 1996. Organic acid metabolism under different glucose concentrations of Leuconostoc oenos from wine. The Journal of Applied Bacteriology 81, 393-397.

Salou, P. Loubiere, P. Pareilleux, A 1994. Growth and energetics of Leuconostoc oenos during co-metabolism of glucose with citrate or fructose. Applied and Environmental Microbiology 60, 1459-1466.

van Beek, S., Priest, F., 2000. Decarboxylation of substituted cinnamic acids by lactic acid bacteria isolated during malt whisky fermentation. Applied and Environmental Microbiology 66, 5322-5328.

Wisselink, H.W., Weusthuis, R.A., Eggink, G., Hugenholtz, J., Grobben, G.J., 2002. Mannitol production by lactic acid bacteria: a review. International Dairy Journal 12, 151-161. 